\title{
Soft corals collected from Jeju Island inhibits the a-MSH-induced melanogenesis in B16F10 cells through activation of ERK
}

K. K. Asanka Sanjeewa ${ }^{1 \dagger}$, Young-jin Park ${ }^{2 \dagger}$, I. P. Shanura Fernando ${ }^{1}$, Yong-Seok Ann ${ }^{3}$, Chang-lk Ko ${ }^{3}$, Lei Wang ${ }^{1}$, You-Jin Jeon ${ }^{1 *}$ and WonWoo Lee ${ }^{1 *}$

\begin{abstract}
In the present study, we first evaluated the melanin inhibitory effect of four crude $70 \%$ ethanol extracts separated from soft corals abundantly growing along the seawaters of Jeju Island, South Korea, including Dendronephthya castanea (DC), Dendronephthya gigantea (DG), Dendronephthya puetteri (DP), and Dendronephthya spinulosa (DS). Among the four ethanol extracts, the ethanol extract of DP (DPE) did not possess any cytotoxic effect on B16F10 cells. However, all other three extracts showed a cytotoxic effect. Also, DPE reduced the melanin content and the cellular tyrosinase activity without cytotoxicity, compared to the a-MSH-stimulated B16F10 cells. Specifically, DPE downregulated the expression levels of tyrosinase and microphthalmia-associated transcription factor by activating the ERK signaling cascade in a-MSH-stimulated B16F10 cells. Interestingly, the melanin inhibitory effect of DPE was abolished by the co-treatment of PD98059, an ERK inhibitor. According to these results, we suggest that DPE has whitening capacity with the melanin inhibitory effects by activating ERK signaling and could be used as a potential natural melanin inhibitor for cosmeceutical products.
\end{abstract}

Keywords: Dendronephthya puetteri, Soft corals, Melanin inhibition, B16F10 cells

\section{Backgrounds}

Melanin is a photo-protective pigment which present in different human organs such as the skin, hair, eye, and brain. The melanin production is useful to protect the human skin from ultraviolet (UV)-induced DNA damage by absorbing UV radiation and other malfunctions caused by UV (Park et al. 2009). The level of melanin biosynthesis in human skins depends on various factors such as the exposure to sunlight, genetic influences, pregnancy, estrogen-progesterone therapies, thyroid dysfunction, cosmetics, and some drugs. Generally, in Asian countries, women prefer fair skin over the dark. However, uncontrolled and high level of melanin production in the skin is a common problem of the people living in Asian countries (Sehgal et al. 2011; Boonme et al. 2009;

\footnotetext{
* Correspondence: youjinj@jejunu.ac.kr; 21cow@jejunu.ac.kr

${ }^{\dagger}$ K. K. Asanka Sanjeewa and Young-jin Park contributed equally to this work.

'Laboratory of Marine Bioresource Technology, Department of Marine Life

Science, School of Marine Biomedical Sciences, Jeju National University, Jeju 63243, Republic of Korea

Full list of author information is available at the end of the article
}

Nasr Bouzaiene et al. 2016). In addition to the determination of skin tone and skin protection, studies have also proved that the accumulation of melanin pigment have a potential to induce the healthcare problems such as freckles, solar lentigo, melisma, ephelides, age spots, and post-inflammatory pigmentation (Huang et al. 2016b; Hridya et al. 2016). Thus, skin-whitening products, specifically in Asia and the rest of the world, are becoming the largest and continually growing segment in the skin care market (Boonme et al. 2009).

Synthesis and distribution of melanin in the epidermis depend on a number of endogenous and exogenous stimuli such as $\alpha$-melanocyte-stimulating hormone $(\alpha-\mathrm{MSH})$ and UV radiation (Park et al. 2009). The melanin synthesis in mammalian skins is mainly regulated by tyrosinase family enzymes. Tyrosinase is a copper-containing enzyme which catalyzes the hydroxylation of l-tyrosine to l-dihydroxyphenylalanine (l-DOPA). Then, DOPA oxidized into DOPA-quinone is responsible for the dark skin tone. Moreover, genes in mammals transcript the tyrosinase, tyrosinase-related protein-1 (TRP-1), 
TRP-2, and microphthalmia-associated transcription factor (MITF) (Kim et al. 2016). Tyrosinase, TRP-1, and TRP-2 are essential to catalyze the melanogenesis process, and MITF induces the expression of melanogenic genes, such as tyrosinase, TRP-1, and TRP-2 (Vachtenheim et al. 2001; Kim et al. 2016; Pillaiyar et al. 2017). Thus, compounds capable to inhibit tyrosinase, TRP-1, and TRP-2 might have a potential to be developed as medicines to treat pigmentation-related disorders and as a whitening agent. During the last few decades, arbutin, azelaic acid, and kojic acid are used as the active ingredients in skin-whitening products as tyrosinase inhibitors (Huang et al. 2016b). However, the adverse side effects associated with synthetic tyrosinase inhibitors such as genotoxicity, erythema, neurodegenerative diseases, and dermatitis urge the requirement of novel tyrosinase inhibitors with less side effects (Wu et al. 2015b; Huang et al. 2016b).

Marine organisms have gained considerable attention due to the promising health-promoting effects associated with secondary metabolites present in the marine organism (Ebada et al. 2008). Soft corals are interesting marine organisms with many bioactive properties such as antioxidant, anti-inflammation, antibacterial, and anticancer (Roy et al. 2016). A number of studies have reported that the secondary metabolites present in soft corals have a potential to be developed as melanin inhibitors (Wu et al. 2015a). However, few reports have been published on in vivo melanin inhibition effects of soft corals which grow around Jeju Island. Therefore, in the present study, authors attempted to evaluate in vitro melanin inhibitory properties and its underlying mechanisms using a crude (70\% ethanol) extract separated from several soft coral species on $\alpha-\mathrm{MSH}$-stimulated B16F10 cells.

\section{Methods}

\section{Chemicals}

Dulbecco's modified Eagle medium (DMEM), fetal bovine serum (FBS), and penicillin-streptomycin $(10,000 \mathrm{U} / \mathrm{mL})$ purchased from Life Technologies Corporation, Grand Island, NY, USA. 3-(4, 5-Dimethylthiazol-2-yl)-2, 5-diphenyltetrazolium bromide (MTT), dimethyl sulfoxide (DMSO), 2-(2-amino-3-methoxyphenyl)-4H-1-benzopyran-4-one (PD98059), and $\alpha$-melanocyte-stimulating hormone $(\alpha-M S H)$ were purchased from Sigma-Aldrich (St. Louis, MO, USA). Prime Script ${ }^{\mathrm{tm}}$ first-strand cDNA synthesis kit for cDNA synthesis was purchased from TaKaRa, Japan. All other chemicals and reagents used in these experiments were of analytical grade.

\section{Sample collection and identification}

Dendronephthya castanea (D. castanea, DC), Dendronephthya gigantea (D. gigantean, DG), D. puetteri (DP), and Dendronephthya spinulosa (D. spinulosa, DS) were collected during April and May 2016 along the Coast of Jeju Island, South Korea. The samples were identified by the Jeju Biodiversity Research Institute (Jeju, South Korea).

\section{Analysis of chemical composition of soft corals}

The ash content was obtained by dry ashing at $550{ }^{\circ} \mathrm{C}$ for $6 \mathrm{~h}$ using dry-type furnace (Horwitz and Latimer 2005). Protein and lipid contents of freeze-dried soft coral samples (raw materials) were determined using Kjeldahl and Soxhlet method (Pasławski and Migaszewski 2006). Liebermann-Burchard method was used to evaluate the sterol content of the ethanol extracts; cholesterol was used as the calibration standard (Xiong et al. 2007) (Table 1).

\section{Preparation of the ethanol extracts from soft corals}

The collected four soft corals were disinfected with $70 \%$ ethanol solution and then washed with running tap water to remove any debris or other attached organisms. Twenty grams of each freeze-dried samples were extracted three times with $2 \mathrm{~L}$ of $70 \%$ ethanol solution for $24 \mathrm{~h}$ at $25{ }^{\circ} \mathrm{C}(100 \mathrm{rpm})$. The liquid layer was separated via vacuum filtration, and the filtrates were concentrated using a rotary evaporator followed by freeze drying. The freeze-dried powder was considered as the crude ethanol extract of DC (DCE), DG (DGE), DP (DPE), and DS (DSE).

\section{Cell culture}

B16F10 cell line was purchased from Korean Cell Line Bank (KCLB; Seoul, South Korea). B16F10 cells were grown in DMEM supplemented with $10 \%$ heat-inactivated FBS, 1\% streptomycin-penicillin. Cells were incubated under $5 \% \mathrm{CO}_{2}$ at $37{ }^{\circ} \mathrm{C}$ (Sanyo MCO-18AIC CO $\mathrm{Cn}_{2}$ Incubator; Moriguchi, Japan). Cultured cells from passages 4-6 were used for the experiments.

\section{Cell viability assay}

The cytotoxicity of soft coral extracts to B16F10 cells was evaluated via the colorimetric MTT assay as described by Mosmann (Mosmann 1983), with slight modifications. Briefly, the cells $\left(2 \times 10^{5}\right.$ cells $\left./ \mathrm{mL}\right)$ were seeded in a 96-well plate and incubated for $24 \mathrm{~h}$. Then, the cells were treated with soft coral extracts $(25,50$, 100 , and $200 \mu \mathrm{g} / \mathrm{mL}$ ) for $48 \mathrm{~h}$. Fifty microliters of MTT solution $(2.0 \mathrm{mg} / \mathrm{mL})$ prepared in PBS was added $2 \mathrm{~h}$ before culture termination. Then, the culture medium was discarded, and $200 \mu \mathrm{L}$ of $100 \%$ DMSO was added to each well to solubilize the formazan. At $540 \mathrm{~nm}$, absorbance was measured using The Synergy ${ }^{\text {min }}$ HT, Vermont, USA, plate reader. The LPS-induced group is used as control in calculating percentage cell viability. The optical density of the formazan generated in non-treated control cells was considered to represent $100 \%$ viability. 
Table 1 Proximate chemical composition of soft coral samples, extraction efficiency, and sterol content of $70 \%$ ethanol extracts separated from soft coral samples

\begin{tabular}{lllllll}
\hline & \multicolumn{2}{l}{ In freeze died soft coral powder } & & \multicolumn{2}{l}{ 70\% ethanol extract } \\
\cline { 2 - 3 } & Ash (\%) & Lipids (\%) & Protein (\%) & & Extraction efficiency (\%) & Sterol content (\%) \\
\hline D. castanea (DC) & $72.29 \pm 1.18$ & $1.25 \pm 0.14$ & $12.84 \pm 1.65$ & & $22.57 \pm 0.12$ & $1.39 \pm 0.14$ \\
D. gigantea (DG) & $59.04 \pm 1.93$ & $1.29 \pm 0.08$ & $15.94 \pm 0.71$ & & $37.18 \pm 2.45$ & $1.34 \pm 0.12$ \\
D. puetteri (DP) & $73.14 \pm 0.81$ & $1.24 \pm 0.09$ & $12.34 \pm 0.52$ & & $14.97 \pm 0.97$ & $1.47 \pm 0.17$ \\
D. spinulosa (DS) & $65.43 \pm 0.43$ & $0.75 \pm 0.15$ & $17.82 \pm 0.22$ & & $17.95 \pm 1.97$ & $0.91 \pm 0.09$ \\
\hline
\end{tabular}

The data are expressed as mean percentages of the viable cells versus the respective control.

\section{Measurement of cellular melanin content}

The intracellular melanin content was quantified by using the previously described method with slight modification (Yoon et al. 2010). B16F10 cells were stimulated with $\alpha-\mathrm{MSH}(100 \mathrm{nM})$ and incubated with DPE showing nontoxic effect and/or the ERK inhibitor PD98059 $(10 \mu \mathrm{M})$ for $48 \mathrm{~h}$. The cell pellets were washed with ice cold PBS and harvested. Then, the harvested cells were dissolved in $2 \mathrm{~N} \mathrm{NaOH}$ containing $10 \% \mathrm{DMSO}$ at $80{ }^{\circ} \mathrm{C}$ for $45 \mathrm{~min}$, and the melanin contents were analyzed at $475 \mathrm{~nm}$ using ELISA reader.

\section{Measurement of tyrosinase activity}

Tyrosinase activity of DPE was quantified according to the previously described method with slight modifications (Kim et al. 2007). Briefly, B16F10 cells were first stimulated with $\alpha-\mathrm{MSH}$ and then treated with DPE with or without PD98059 $(10 \mu \mathrm{M})$. After $48 \mathrm{~h}$ incubation, cells were washed with ice cold PBS and suspended in a lysis buffer prepared from PBS (Triton-X $1001.0 \%$ $1 \mu \mathrm{g} / \mathrm{mL}$ leupeptin and $100 \mu \mathrm{g} / \mathrm{mL}$ PMSF), then incubated at $4{ }^{\circ} \mathrm{C}$ for $20 \mathrm{~min}$ to yield cell lysates. The cell lysates were centrifuged at $10,000 \times g$ for $10 \mathrm{~min}$. The protein content of all samples was quantified using the Pierce $^{\mathrm{Tu}}$ BCA Protein Assay Kit (Thermo Scientific, Rockford, IL, USA) and normalized. Then, $90 \mu \mathrm{L}$ of cell extract was placed in a 96-well plate treated with freshly prepared $10 \mu \mathrm{L}$ of l-DOPA (final concentration of $1 \mathrm{mmol} / \mathrm{L}$ ) in $25 \mathrm{mM}$ phosphate buffer ( $\mathrm{pH} \mathrm{6.8)}$ and incubated at $37{ }^{\circ} \mathrm{C}$ for $1 \mathrm{~h}$. Absorbance was measured at $405 \mathrm{~nm}$ using an ELISA reader.

\section{Western blot analysis}

B16F10 cells $\left(2.5 \times 10^{5}\right.$ cells $)$ were seeded into six-well plates and incubated with DPE. Cells were washed with cold PBS, and cytosolic proteins were extracted from the cells with cytoplasmic extraction kit (Thermo Scientific, IL, Rockford, USA). Protein contents of total cell lysates were determined using BCA protein assay (Sigma-Aldrich, St. Louis, MO, USA). After separation on a $10 \%$
SDS-polyacrylamide gel under denaturing conditions, the cytoplasmic proteins $(40 \mu \mathrm{g})$ were electro-transferred onto a nitrocellulose membrane. After blocking with 5\% nonfat milk for $2 \mathrm{~h}$, the blots were separately incubated with antibodies such as tyrosinase, ERK, p-ERK, or $\beta$-actin (Cell Signaling Technology, Beverly, MA, USA). The blots were washed twice with tween 20/Tris-buffered saline (TTBS) and then incubated with HRP-conjugated anti-mouse or anti-rabbit IgG for 45 min. Antibody binding was visualized by using enhanced chemiluminescence (ECL) reagents (Amersham, Arlington Heights, IL, USA). The relative expression of each protein were normalized by analyzing the level of $\beta$-actin or nucleolin protein by using ImageJ program.

\section{Total RNA extraction and CDNA synthesis}

Total RNA was separated from the B16F10 cells with Tri-Reagent ${ }^{\text {tw }}$ (Sigma-Aldrich, St. Louis, MO, USA) using the manufacturer's instruction. Absorbance values at 260 and $280 \mathrm{~nm}$ were measured using a $\mu$ Drop Plate (Thermo Scientific, IL, Rockford, USA) to determine the concentration and purity of RNA samples. After the quantification, $1 \mu \mathrm{g}$ of extracted RNA from each sample was used for the synthesis of cDNA. Synthesized cDNA was then diluted 40 -fold and stored at $-80^{\circ} \mathrm{C}$.

\section{Quantitative real-time polymerase chain reaction analysis} The mRNA expression levels of tyrosine and MIFF were analyzed by using SYBR Green quantitative real-time PCR technique with the Thermal Cycler Dice Real Time System (TaKaRa, Japan). GAPDH was used as internal reference gene in amplification. All the primers used in this study were purchased from Bioneer, Seoul, South Korea, and the sequence of each primer are indicated in Table 2. Reactions were carried out in a $10 \mu \mathrm{L}$ volume containing $3 \mu \mathrm{L}$ diluted cDNA template, $5 \mu \mathrm{L}$ of $2 \times$ TaKaRa ExTaq ${ }^{\text {Th }}$ SYBR premix, $0.4 \mu \mathrm{L}$ each of the forward and reverse primers $(10 \mu \mathrm{M})$, and $1.2 \mu \mathrm{L} \mathrm{ddH}_{2} \mathrm{O}$. Briefly, the reaction was performed using the following profile: one cycle at $95{ }^{\circ} \mathrm{C}$ for $10 \mathrm{~s}$, followed by 45 cycles at $95{ }^{\circ} \mathrm{C}$ for $5 \mathrm{~s}, 55^{\circ} \mathrm{C}$ for $10 \mathrm{~s}$, and $72{ }^{\circ} \mathrm{C}$ for $20 \mathrm{~s}$, and a final single cycle at $95{ }^{\circ} \mathrm{C}$ for $15 \mathrm{~s}, 55^{\circ} \mathrm{C}$ for $30 \mathrm{~s}$, and $95{ }^{\circ} \mathrm{C}$ for $15 \mathrm{~s}$. Assays were conducted in triplicate. The expression levels of mRANA were calculated by the 
Table 2 Sequence of the primers used in this study

\begin{tabular}{lll}
\hline Gene & & \\
\hline Tyrosine & Sense & 5'-GGCCAGCTTTCAGGCAGAGGT-3' \\
& Antisense & 5'-TGGTGCTTCATGGGCAAAATC-3' \\
MITF & Sense & 5'-GTATGAACACGCACTCTCGA-3' \\
& Antisense & 5'-CGAACGTATTTGCCATTTGC-3' \\
GAPDH & Sense & 5'-AAGGGTCATCATCTCTGCCC-3' \\
& Antisense & 5'-GTGATGGCATGGACTGTGGT-3' \\
\hline
\end{tabular}

Livak ( $2^{-\Delta \Delta C T}$ ) method (Livak and Schmittgen 2001). The base line was automatically set by Dice ${ }^{\mathrm{Tm}}$ Real Time System software (V 2) to maintain consistency. The data are presented as the mean \pm standard error (SE) of the relative mRNA expression from three repeated experiments. The two-tailed unpaired Students $t$ test was used to determine statistical significance $\left(* p<0.05\right.$ and $\left.{ }^{* *} p<0.01\right)$.

\section{Statistical analysis}

Data are expressed as mean \pm standard deviation for three determinations. Analysis of variance (ANOVA) was carried out for the collected data using the Statistical Package for Social Science (IBM SPSS Statistics for Windows, version 20.0). The Duncan's multiple range test was used for the mean separation $\left({ }^{*} p<0.05\right.$ and $\left.{ }^{* * *} p<0.01\right)$.

\section{Results}

Proximate chemical composition of soft coral samples and their extraction yields

According to the results, the ash content of soft coral samples ranged between the 59 and $73 \%$ from their total dry weight (Table 1). In parallel to our observation, previously, Gori et al. (2013) also reported that the biochemical composition of soft corals ranged between 25 and $35 \%$. The previous studies and our results suggest that soft corals contain a low amount of organic matters compared to the inorganic matter composition in its biomass (Gori et al. 2013). Lipid contents of the tested soft corals were very low (less than $2 \%$ ), and protein content was ranged between 12 and $18 \%$ from their dry weight. Soft coral samples were extracted with $70 \%$ ethanol solution to get crude $70 \%$ ethanol extract from soft coral samples. The extraction efficiency of DCE, DGE, DPE, and DSE was $22.57 \pm 0.12 \%, 37.18 \pm 2.45 \%, 14.97 \pm$ $0.97 \%$, and $17.95 \pm 1.97 \%$, respectively. The proximate composition of soft corals and sterol contents of $70 \%$ ethanol extracts were reported in Table 1.

\section{Cytotoxicity of soft coral extracts on B16F10 cells}

Before studying the melanin inhibitory effects, we compared the cytotoxicity of the four ethanol extracts obtained from soft coral samples. MTT colorimetric assay was performed to measure the reduction of cell viability after treatment with DCE, DGE, DPE, or DSE $(0$ $200 \mu \mathrm{g} / \mathrm{mL}$ ) for $48 \mathrm{~h}$. At the concentration of 100 and $200 \mu \mathrm{g} / \mathrm{mL}$, respectively, DCE and DGE had significant cytotoxic effects on B16F10 cells. All the treated concentrations of DSE had a strong toxic effect on B16F10 cells. Moreover, at the concentration of $200 \mu \mathrm{g} / \mathrm{mL}$, DSE decreased the cell viability of B16F10 cells over 40\%, compared to the untreated group (Fig. 1). However, DPE did not show any cytotoxic effects on B16F10 cells at investigated concentration range (up to $200 \mu \mathrm{g} / \mathrm{mL}$ ).

\section{Effect of DPE on melanin synthesis in B16F10 melanoma cells}

Before studying the effect of DPEs on melanogenesis, we evaluated the effect of DPE on the viability of $\alpha-\mathrm{MSH}$-stimulated B16F10 cells. As shown in the Fig. 2a, exposure of $\alpha-\mathrm{MSH}(100 \mathrm{nM})$ did not show any cytotoxicity in B16F10 cells, compared to the control group. Also, the treatment of DPE alone $(50 \sim 200 \mu \mathrm{g} / \mathrm{mL})$ did not affect the viability of $\alpha-\mathrm{MSH}$-stimulated B16F10 cells, compared to the control group. As the next experiment, we studied the melanin inhibitory effect of DPE in $\alpha$-MSH-stimulated B16F10 cells (Fig. 2b). The results showed that the cellular melanin content of

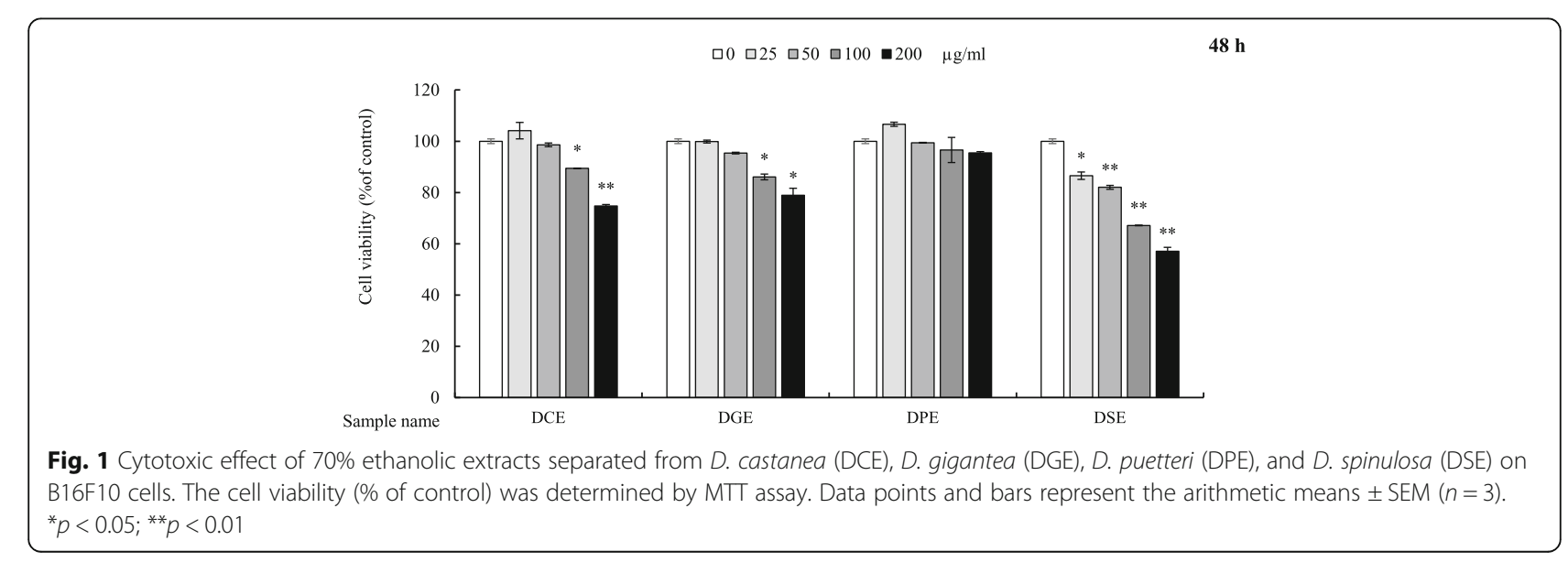




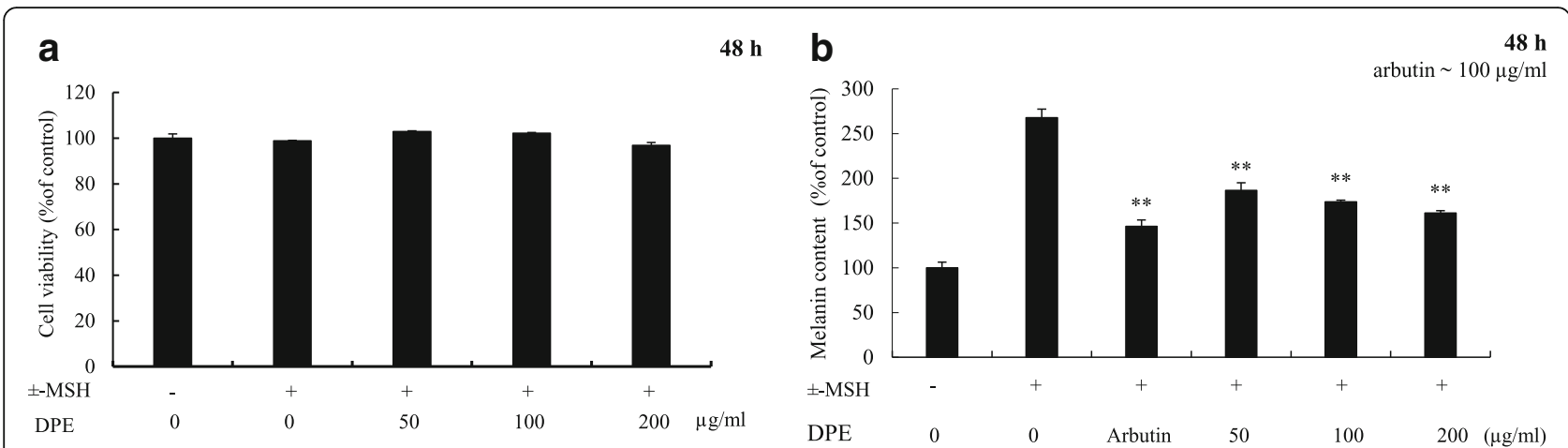

Fig. 2 Cytotoxic and melanin inhibitory effect of D. puetteri ethanolic extract (DPE) on B16F10 cells. a Cytotoxicity of a-MSH and DPE on B16F10 cells. b Melanin inhibitory effect of DPE on a-MSH-stimulated B16F10 cells. Cells were cultured with $0 \sim 200 \mu \mathrm{g} / \mathrm{mL}$ of DPE for $48 \mathrm{~h}$. After incubation, the melanin content was analyzed. Melanin content results are presented as the percentage to non-treated group. Data points and bars represent the arithmetic means $\pm \operatorname{SEM}(n=3) .{ }^{*} p<0.05 ;{ }^{* *} p<0.01$

$\alpha$-MSH-stimulated cells was dramatically increased, compared to the non-treated control. However, DPE dose-dependently reduced the melanin production caused by the stimulation of $\alpha-\mathrm{MSH}$ in B16F10 cells, and in particular, the effect of DPE at $200 \mu \mathrm{g} / \mathrm{mL}$ was similar to the melanin inhibitory effect of arbutin used as a positive control in this study.

\section{Tyrosinase inhibitory activity of DPE in B16F10 cells}

Tyrosinase is a copper-containing enzyme, considered as a key enzyme in melanogenesis (Seo et al. 2003). Thus, most cosmetics products contain tyrosinase inhibitors in order to inhibit the melanin production in the skin (Sanjeewa et al. 2016). In the present study, we attempted to quantify the cellular tyrosinase content in $\alpha$-MSH-stimulated B16F10 cells with DPE and arbutin. According to the results, DPE dose-dependently and significantly inhibited the cellular tyrosinase, compared to the $\alpha$-MSH-stimulated B16F10 cells (Fig. 3). These results indicate DPE has melanin and tyrosinase inhibitory effects.
Effect of DPE on mitogen-activated protein kinase associated ERK protein expression and tyrosinase protein expression

We next attempted to investigate the effects of DPE on tyrosinase protein inhibition against $\alpha$-MSH-stimulated B16F10 cells (Fig. 4a). In addition, we used selective ERK inhibitor PD98059 to understand the effects of DPE on ERK protein expression in B16F10 cells (Fig. 4b). According to the results, DPE significantly inhibited the elevated tyrosinase protein levels compared to the $\alpha-\mathrm{MSH}$-stimulated B16F10 cells. However, in this study, we observed exposure of B16F10 cells to PD98059 before the DPE treatment decreased the downregulatory effect of DPE on tyrosinase expression. These results suggest that the tyrosinase inhibitory effect of DPE might due to the inhibition of ERK signaling cascades. Therefore, we studied the effect of DPE on phosphorylation status of ERK42/44 using western blot analysis as shown in Fig. 4b. According to the results, it is clear that the treatment of DPE potentially increased the phosphorylation of ERK

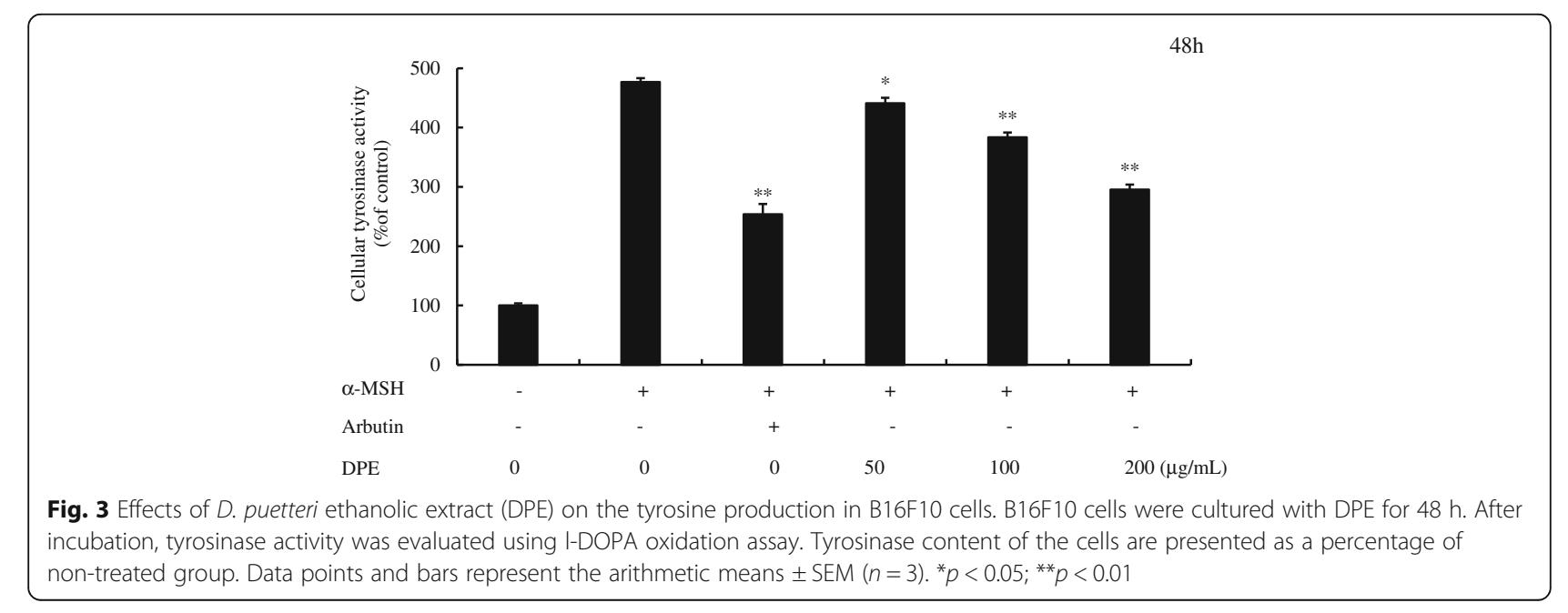



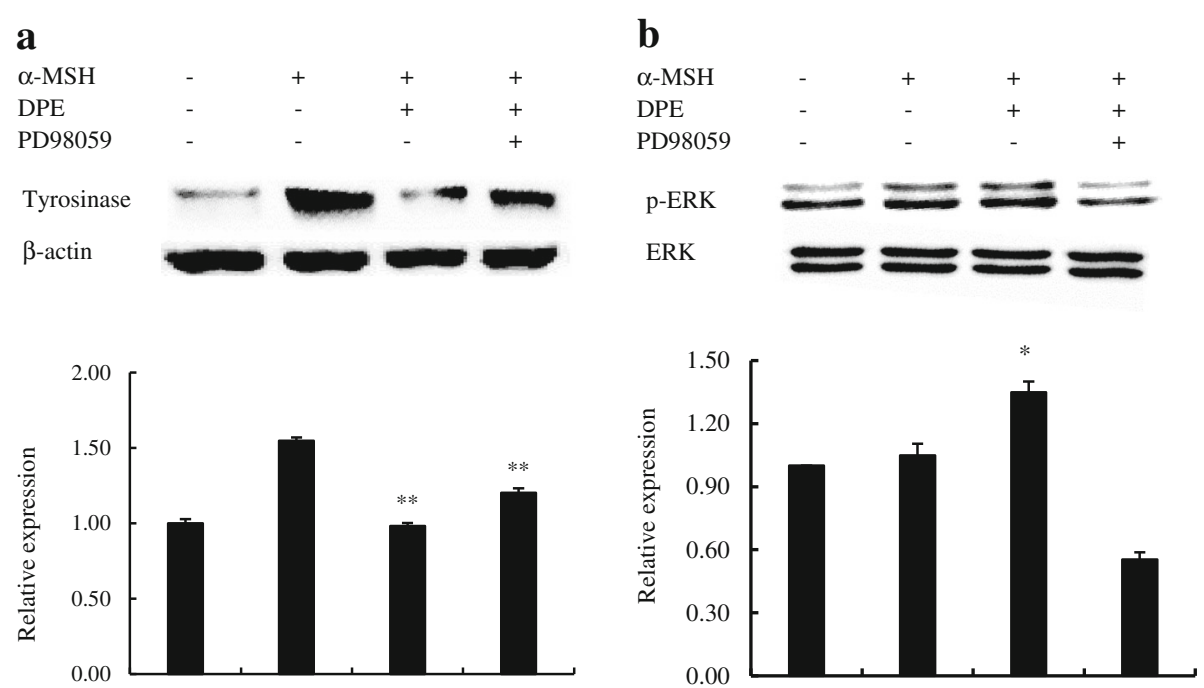

Fig. 4 Effect of D. puetteri ethanolic extract on tyrosinase and ERK pathway associated protein expression in a-MSH-stimulated B16F10 cells. Cells were incubated with a-MSH (100 nM) together with DPE $(200 \mu \mathrm{g} / \mathrm{mL})$ for $48 \mathrm{~h}$ in the absence or presence of PD98059 $(10 \mu \mathrm{M})$. a Tyrosinase, b ERK, and $p$-ERK protein expressions were visualized by Western blotting. Data points and bars represent the arithmetic means \pm SEM $(n=3)$ $\left({ }^{*} p<0.05 ;{ }^{* *} p<0.01\right)$

compared to the $\alpha$-MSH-stimulated B16F10 cells. Specifically, similar to the tyrosinase inhibitory results, PD98059 decreased the upregulated p-ERK expression by DPE. These results suggest that DPE has a potential to inhibit the melanogenesis in $\alpha$-MSH-stimulated B16F10 cells via modulating $\mathrm{p} 42 / 44$ mitogen-activated protein kinase (MAPK) signaling cascade.

\section{Effect of DPE on the expression of melanogenic genes in B16F10 cells}

To study the effect of DPE on melanogenic gene expression levels in $\alpha$-MSH-stimulated B16F10 cells, we performed qPCR. As shown in the Fig. 5a, b, both tyrosinase and MITF genes were dramatically increased in response to the $\alpha-\mathrm{MSH}$. However, with the treatment of DPE $(200 \mu \mathrm{g} / \mathrm{mL})$, it decreased the elevated expression levels of tyrosinase and MITF genes in $\alpha$-MSH-stimulated B16F10 cells. In addition, treatment of ERK inhibitor PD98059 prior to DPE exposure reduces the inhibitory effect of DPE on both melanogenesis gene expression.

\section{Discussion}

Various extraction methods can be employed to isolate functional materials from the plant material such as ultrasound-assisted extraction, microwave-assisted extraction (MAE), supercritical fluid extraction (SFE), and organic solvent extraction (OSE) (Wijesinghe and Jeon 2012). However, application of the aforementioned
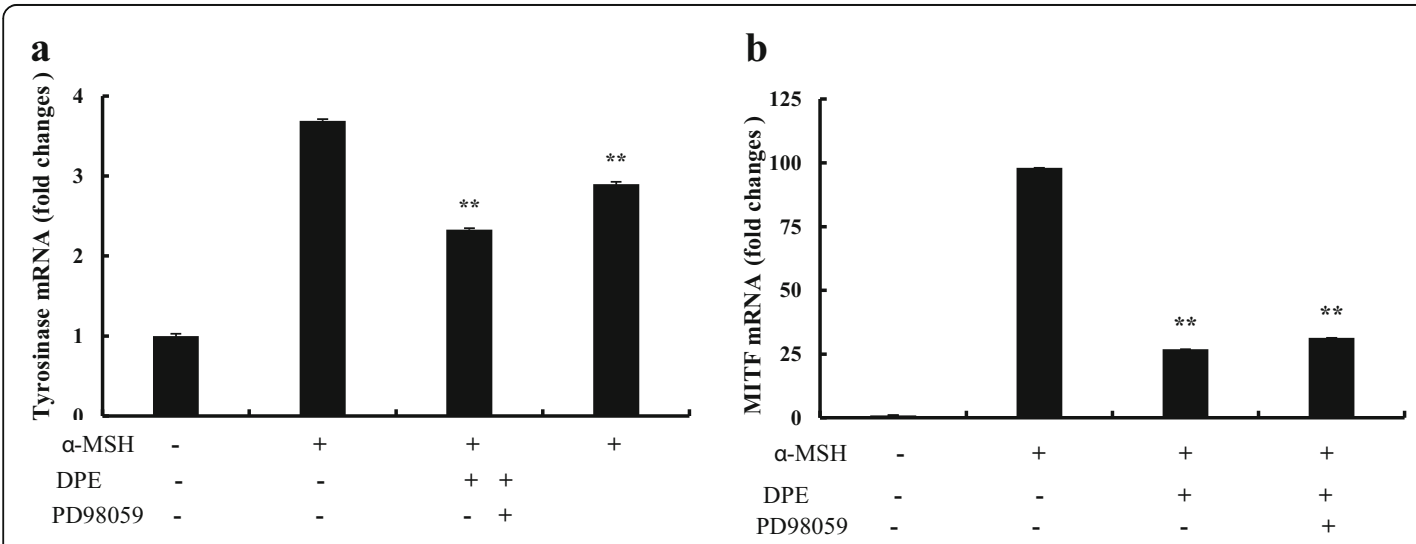

Fig. 5 Inhibitory effect of D. puetteri ethanolic extract (DPE) on melogenic gene expression in a-MSH-stimulated B16F10 melanoma cells. Effect of DPE on a tyrosinase and $\mathbf{b}$ MITF gene expression. Cells were exposed to $100 \mathrm{nM}$ a-MSH in the presence and absence of DPE $(200 \mu \mathrm{gg} / \mathrm{mL}) \mathrm{and}$ PD98059 $(10 \mu \mathrm{M})$. Tyrosinase and MITF mRNA levels were examined by real-time RT-PCR using GAPDH as an internal control. Results represent the pooled mean \pm SE of three independent experiments, performed in triplicate. ${ }^{*} p<0.05,{ }^{* *} p<0.01$ 
extraction methods to isolate bioactive compounds from natural sources has several disadvantages such as degradation of active compounds (MAE), high cost (SFE), and environmental pollution (OSE) (Wang and Weller 2006). However, according to the previous studies, ethanol-aided extraction is one of the promising extraction method to isolate bioactive metabolites from natural organisms due to its lower toxicity, low cost, and less environmental pollution (Wijesinghe and Jeon 2012; Wang and Weller 2006). With the support of previous scientific evidences, we extracted soft coral (DC, DG, DP, and DS) species into $70 \%$ ethanol solution to explore their potential to be developed as a cosmeceutical. According to the results, extraction efficiency of soft corals ranged between 14 and 37\% (Table 2). Even though high extraction efficiency is an important factor for industrial level extractions, the extracted materials should be bio-compatible to use them in commercial applications such as cosmeceutical and nutraceutical. Thus, low or nontoxic effect of the active ingredient towards the human organs is one of the important factors to consider in the functional product formulation (Antonopoulou et al. 2016).

Generally, proper melanin level protects the human skin from damages induced by UV, toxic drugs, and chemicals such as $\alpha$-MSH (Taylor 2002; Sanjeewa et al. 2016). However, excessive production of melanin is responsible for the development of melanoma skin cancer and dark spots on the skin (Taylor 2002; Sanjeewa et al. 2016). Many researchers have used B16F10 cells to evaluate melanin inhibitory effect of natural products. B16F10 is a murine cell line which is capable to synthesize both melanin and tyrosinase by stimulation of $\alpha-\mathrm{MSH}$ to evaluate melanin inhibitory effect of natural products (Chan et al. 2011). According to the MTT colorimetric assay results, DCE, DGE, and DSE had considerable cytotoxic effect on B16F10 cells within the tested concentrations. In parallel to our observations, a number of studies have reported that the extracts of soft coral had cytotoxicity to the cancer cells and to the other normal cell lines (Huang et al. 2016a). Therefore, after considering cytotoxicity of extracts, DPE was used for further studies because of its nontoxic effect on B16F10 cells.

Arbutin, a beta-D-glucopyranoside of hydroquinone, is an effective commercial melanin inhibitor which is used to treat cutaneous hyperpigmentation characterized by hyperactive melanocyte functions (Maeda and Fukuda 1996; Rendon and Gaviria 2005). So, we compared the melanin inhibitory effect of DPE with arbutin to get a clear idea about melanin and tyrosinase inhibitory effects of DPE. According to our results, melanin production caused by stimulation of $\alpha-\mathrm{MSH}$ in B16F10 cells and, in particular, the effect of DPE at $200 \mu \mathrm{g} / \mathrm{mL}$ was not significantly different to the melanin inhibitory effect of arbutin used as a positive control in this study. Moreover, DPE dose-dependently inhibited the cellular tyrosinase production under tested conditions. However, inhibitory effect of DPE on melanin and tyrosinase might increase with the further purification of $70 \%$ ethanol extract, and we are currently working to isolate active compound.

MITF is an important transcription factor, which is capable of regulating pigmentation, proliferation, and survival of melanocytes (Steingrímsson et al. 1994). Upregulated expression of MITF triggers the expression of melanogenesis genes such as tyrosinase (Kim et al. 2016; Vachtenheim et al. 2001; Pillaiyar et al. 2017). The MAPK/ERK signaling cascade is capable of monitoring the proliferation and differentiation of cells. During the melanogenesis process, ERK-associated proteins control the expression levels of MITF protein. Specifically, upregulated expression of ERK inhibits the MITF protein expression in melanocytes (Bae et al. 2016). Previously, a number of studies reported that phosphorylation of MAPK signaling cascade-associated proteins have a potential to weaken the expression of genes and proteins of MITF (Hwang et al. 2017). Taken together, induction of phosphorylation of ERK-associated signal molecules is a key point of inhibition of melanogenesis. Thus, as the next step, we studied the effect of DPE $(200 \mu \mathrm{g} / \mathrm{mL})$ on MAPK/ERK protein expression levels using western blot analysis and MITF gene expression using qPCR. With our results, we can confirm that DPE has a potential to regulate melanin synthesis in B16F10 cells via upregulating $\mathrm{p}$-ERK protein expression in $\alpha$-MSH-stimulated B16F10 cells. Further studies are needed to investigate active compound in DPE responsible for melanin inhibitory effect observed in this study.

\section{Conclusions}

In the present study, we demonstrated the crude ethanolic extract separated from DPE has a potential to inhibit the melanin synthesis in $\alpha-\mathrm{MSH}$-stimulated B16F10 cells via regulating MAPK-associated P42/44 protein expression. According to the western blot analysis results, and mRNA gene expression profiles, we can conclude that DPE is a potential candidate to be developed as a de-pigmenting compound. To the best of our knowledge, this is the first report to mention on potential melanin inhibitory activity of $D$. puetteri crude extract.

\section{Abbreviations}

DC: Dendronephthya castanea; DG: Dendronephthya gigantea; DMEM: Dulbecco's modified Eagle medium; DMSO: Dimethyl sulfoxide;

DP: Dendronephthya puetteri; DS: Dendronephthya spinulosa; FBS: Fetal bovine 
serum; I-DOPA: Hydroxylation of I-tyrosine to I-dihydroxyphenylalanine; MTT: 3 (4, 5-Dimethylthiazol-2-yl)-2, 5-diphenyltetrazolium bromide; PD98059: 2-(2Amino-3-methoxyphenyl)-4H-1-benzopyran-4-one; TRP: Tyrosinase-related protein-1; UV: Ultraviolet; a-MSH: a-Melanocyte-stimulating hormone

\section{Acknowledgements}

This research was financially supported by the Ministry of Trade, Industry, and Energy (MOTIE), South Korea, under the "Regional Specialized Industry Development Program" supervised by the Korea Institute for Advancement of Technology (KIAT).

\section{Funding}

This research was financially supported by the Ministry of Trade, Industry, and Energy (MOTIE), South Korea.

\section{Availability of data and materials}

All data sets generated and/or analyzed during the current study are available from the corresponding author on reasonable request.

\section{Authors' contributions}

KKAS, IPSP, WWL, and YJJ designed this study and drafted and also revised the manuscript. YJP, YSA, and CIK conceived the study. All authors read and approved the final manuscript.

\section{Ethics approval and consent to participate}

Not applicable.

\section{Competing interests}

The authors declare that they have no competing interests.

\section{Publisher's Note}

Springer Nature remains neutral with regard to jurisdictional claims in published maps and institutional affiliations.

\section{Author details}

'Laboratory of Marine Bioresource Technology, Department of Marine Life Science, School of Marine Biomedical Sciences, Jeju National University, Jeju 63243, Republic of Korea. ${ }^{2}$ Department of Family Medicine, College of Medicine, Dong-A University, Dong-A University Medical Center, Busan 602-715, Republic of Korea. ${ }^{3}$ Choung Ryong Fisheries Co. Ltd, 7825, LiJuudong-ro, Namwon-eup, Seogwipo-Si, Jeju, Republic of Korea.

Received: 13 March 2018 Accepted: 14 May 2018

Published online: 06 September 2018

\section{References}

Antonopoulou I, Varriale S, Topakas E, Rova U, Christakopoulos P, Faraco V. Enzymatic synthesis of bioactive compounds with high potential for cosmeceutical application. Appl Microbiol Biotechnol. 2016;100:6519-43.

Bae JS, Han M, Yao C, Chung JH. Chaetocin inhibits IBMX-induced melanogenesis in B16F10 mouse melanoma cells through activation of ERK. Chem Biol Interact. 2016:245:66-71.

Boonme P, Junyaprasert VB, Suksawad N, Songkro S. Microemulsions and nanoemulsions: novel vehicles for whitening cosmeceuticals. J Biomed Nanotechnol. 2009;5:373-83.

Chan YY, Kim KH, Cheah SH. Inhibitory effects of Sargassum polycystum on tyrosinase activity and melanin formation in B16F10 murine melanoma cells. J Ethnopharmacol. 2011:137:1183-8.

Ebada SS, Edrada RA, Lin W, Proksch P. Methods for isolation, purification and structural elucidation of bioactive secondary metabolites from marine invertebrates. Nat Protoc. 2008;3:1820-31.

Gori A, Linares C, Viladrich N, Clavero A, Orejas C, Fiorillo I, Ambroso S, Gili J-M, Rossi S. Effects of food availability on the sexual reproduction and biochemical composition of the Mediterranean gorgonian Paramuricea clavata. J Exp Mar Biol Ecol. 2013:444:38-45.

Horwitz W, Latimer GW Jr. 2005. Official methods of analysis of AOAC International. 18th ed. Gaithersburg: AOAC International; 2005.

Huang CY, Tseng YJ, Chokkalingam U, Hwang TL, Hsu CH, Dai CF, Sung PJ, Sheu $\mathrm{JH}$. Bioactive isoprenoid-derived natural products from a Dongsha atoll soft coral Sinularia erecta. J Nat Prod. 2016a;79:1339-46.
Huang HC, Liao CC, Peng CC, Lim JM, Siao JH, Wei CM, Chen CC, Wu CS, Chang TM. Dihydromyricetin from Ampelopsis grossedentata inhibits melanogenesis through down-regulation of MAPK, PKA and PKC signaling pathways. Chem Biol Interact. 2016b;258:166-74.

Hwang YS, Kim YJ, Kim MO, Kang M, Oh SW, Nho YH, Park SH, Lee J. Cannabidiol upregulates melanogenesis through CB1 dependent pathway by activating p38 MAPK and p42/44 MAPK. Chem Biol Interact. 2017;273:107-14.

Kim BH, Park KC, Park JH, Lee CG, Ye SK, Park JY. Inhibition of tyrosinase activity and melanin production by the chalcone derivative 1-(2-cyclohexylmethoxy6-hydroxy-phenyl)-3-(4-hydroxymethyl-phenyl)-propenone. Biochem Biophys Res Commun. 2016:480:648-54.

Kim D-S, Jeong Y-M, Park I-K, Hahn H-G, Lee H-K, Kwon S-B, Jeong JH, Yang SJ, Sohn UD, Park K-C. A new 2-imino-1, 3-thiazoline derivative, KHG22394, inhibits melanin synthesis in mouse B16 melanoma cells. Biol Pharm Bull. 2007;30:180-3.

Livak KJ, Schmittgen TD. Analysis of relative gene expression data using real-time quantitative PCR and the 2(-Delta Delta C(T)) method. Methods. 2001;25:402-8.

Maeda K, Fukuda M. Arbutin: mechanism of its depigmenting action in human melanocyte culture. J Pharmacol Exp Ther. 1996;276:765-9.

Mosmann T. Rapid colorimetric assay for cellular growth and survival: application to proliferation and cytotoxicity assays. J Immunol Methods. 1983;65:55-63.

Nasr Bouzaiene N, Chaabane F, Sassi A, Chekir-Ghedira L, Ghedira K. Effect of apigenin-7-glucoside, genkwanin and naringenin on tyrosinase activity and melanin synthesis in B16F10 melanoma cells. Life Sci. 2016;144:80-5.

Park HY, Kosmadaki M, Yaar M, Gilchrest BA. Cellular mechanisms regulating human melanogenesis. Cell Mol Life Sci. 2009;66:1493-506.

Pasławski P, Migaszewski Z. The quality of element determinations in plant materials by instrumental methods. Pol J Environ Stud. 2006;15:154-64.

Pillaiyar T, Manickam M, Jung SH. Downregulation of melanogenesis: drug discovery and therapeutic options. Drug Discov Today. 2017;22:282-98.

Rendon MI, Gaviria Jl. Review of skin-lightening agents. Dermatol Surg. 2005;31: 886-9. discussion 9

Roy PK, Ashimine R, Miyazato H, Taira J, Ueda K. Endoperoxy and hydroperoxy cadinane-type sesquiterpenoids from an Okinawan soft coral, Sinularia sp. Arch Pharm Res. 2016;39:778-84.

Sanjeewa KKA, Kim EA, Son KT, Jeon YJ. Bioactive properties and potentials cosmeceutical applications of phlorotannins isolated from brown seaweeds: a review. J Photochem Photobiol B. 2016:162:100-5.

Sehgal VN, Verma P, Srivastava G, Aggarwal AK, Verma S. Melasma: treatment strategy. J Cosmet Laser Ther. 2011;13:265-79.

Seo SY, Sharma VK, Sharma N. Mushroom tyrosinase: recent prospects. J Agric Food Chem. 2003;51:2837-53.

Steingrímsson E, Moore KJ, Lamoreux ML, Ferré-D'Amaré AR, Burley SK, Zimring DCS, Skow LC, Hodgkinson CA, Arnheiter H, Copeland NG. Microphthalmia (mi) mutations helps explain their developmental and phenotypic consequences. Nat Genet. 1994;8:257.

Taylor SC. Skin of color: biology, structure, function, and implications for dermatologic disease. J Am Acad Dermatol. 2002;46:541-62.

Vachtenheim J, Novotna H, Ghanem G. Transcriptional repression of the microphthalmia gene in melanoma cells correlates with the unresponsiveness of target genes to ectopic microphthalmia-associated transcription factor. J Invest Dermatol. 2001;117:1505-11.

Wang L, Weller CL. Recent advances in extraction of nutraceuticals from plants. Trends Food Sci Technol. 2006;17:300-12.

Wijesinghe WA, Jeon YJ. Enzyme-assistant extraction (EAE) of bioactive components: a useful approach for recovery of industrially important metabolites from seaweeds: a review. Fitoterapia. 2012;83:6-12.

Wu SY, Wang HM, Wen YS, Liu W, Li PH, Chiu CC, Chen PC, Huang CY, Sheu JH, Wen $\mathrm{ZH}$. 4-(Phenylsulfanyl)butan-2-one suppresses melanin synthesis and melanosome maturation in vitro and in vivo. Int J Mol Sci. 2015a;16:20240-57.

Wu Y, Wu ZR, Chen P, Yang L, Deng WR, Wang YQ, Li HY. Effect of the tyrosinase inhibitor (S)-N-trans-feruloyloctopamine from garlic skin on tyrosinase gene expression and melanine accumulation in melanoma cells. Bioorg Med Chem Lett. 2015b;25:1476-8.

Xiong $\mathrm{Q}$, Wilson WK, Pang J. The Liebermann-Burchard reaction: sulfonation, desaturation, and rearrangment of cholesterol in acid. Lipids. 2007;42:87-96.

Yoon W, Kim M, Koh H, Lee W, Lee N, Hyun C. Effect of Korean red sea cucumber (Stichopus japonicus) on melanogenic protein expression in murine B16 melanoma. Int J Pharm. 2010:6:37-42. 